\title{
Automated determination of chest characteristics of Indonesians as the basis of chest dosimetrical phantom design
}

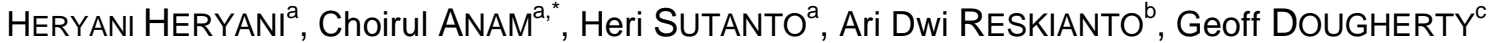 \\ ${ }^{a}$ Department of Physics, Faculty of Sciences and Mathematics, Diponegoro University, Jl. Prof. Soedarto SH, Tembalang, \\ Semarang 50275, Central Java, Indonesia \\ ${ }^{b}$ Kraton Regional General Hospital, Jl. Veteran 31, Pekalongan, Central Java, Indonesia \\ ${ }^{c}$ Department of Applied Physics and Medical Imaging, California State University Channel Islands, Camarillo, CA 93012, \\ USA \\ *E-mail address: anam@fisika.fsm.undip.ac.id
}

\begin{abstract}
Purpose: The purpose of this study was to develop software to automatically measure the main areas of the chest, i.e. soft tissue, bone, and air and to implement it in Kraton Regional General Hospital for designing a specific dosimetrical phantom for chest digital radiography (DR) examination.

Methods: This study was a retrospective study on all DR images from 2015 to 2019, and computed tomography (CT) images of 102 patients in Digital Imaging and Communications in Medicine (DICOM) format files scanned from January-December 2019 at the Kraton Regional General Hospital. We evaluated the number of basic DR chest examinations compared to all DR radiological examinations. We developed a MatLab graphical user interface (GUI) for automated measurement of the areas of the main chest components (soft tissue, bone, and air). We computed the areas of the main components of the chest in order to develop a specific chest phantom for DR in the hospital. In order to compute the areas of the main components, we used chest CT images of patients with clinical indications of chest tumors.

Results: The basic DR chest examination comprised 59.5\% of all DR examinations in the hospital during 2015-2019. The average areas of soft tissue, bone, and air within the chest in all patients were 331,20 , and $125 \mathrm{~cm}^{2}$, respectively, with values of 345,23 , and $139 \mathrm{~cm}^{2}$ for males, and 309,15 , and $103 \mathrm{~cm}^{2}$ for females. The areas were also dependent on age with values of $121,10,55 \mathrm{~cm}^{2}$ for patients aged 5-11 years, 371,27 , and $88 \mathrm{~cm}^{2}$ for patients aged $12-25$ years, 322 , 22 , and $131 \mathrm{~cm}^{2}$ for patients aged $26-45$ years, and 334,19 , and $126 \mathrm{~cm}^{2}$ for patients $>45$ years old.

Conclusion: A GUI for computing the main composition of the chest was successfully developed. The areas of chest male patients were greater than female patients. The areas of soft tissue, bone, and air were dependent on the patient's age. Therefore, the design of dosimetrical DR phantom must consider the gender and age of the patient.
\end{abstract}

Key words: digital radiography; chest examination; chest phantom; dosimetrical phantom.

\section{Introduction}

According to the United Nation Scientific Committee on the Effects of Atomic Radiation (UNSCEAR), x-ray radiation exposure in routine radiological examinations is the biggest component of radiation in medicine, ${ }^{1,2}$ and basic chest examinations are one of the most commonly used procedures in clinical practice and mass screening. ${ }^{3,4}$ The International Commission on Radiation Units \& Measurements (ICRU) reported that chest radiographs ${ }^{4,5}$ represent $25 \%$ of all $\mathrm{x}$-ray examinations carried out. In recent years, most chest examinations employ digital radiography (DR) instead of conventional analog radiography. A good digital image of the chest can be obtained, by selecting appropriate exposure factors (tube voltage, tube current, and irradiation time) to produce optimal radiographic quality with the smallest dose. ${ }^{6}$ Any increase in tube voltage must be followed by a reduction in tube current and irradiation time so that the appropriate radiation intensity to produce a sufficient image quality is employed. ${ }^{7-9}$

The patient dose in a DR examination is an issue highlighted by the Nuclear Energy Regulatory Agency of Indonesia (BAPETEN) and the Indonesian Hospital Accreditation Committee (KARS). The BAPETEN has published a webbased application for recording patient data called SI INTAN, and has established diagnostic-reference levels (DRL) for all diagnostic radiography. The KARS has obligated hospitals to keep patient dose records for accreditation. ${ }^{10}$ 


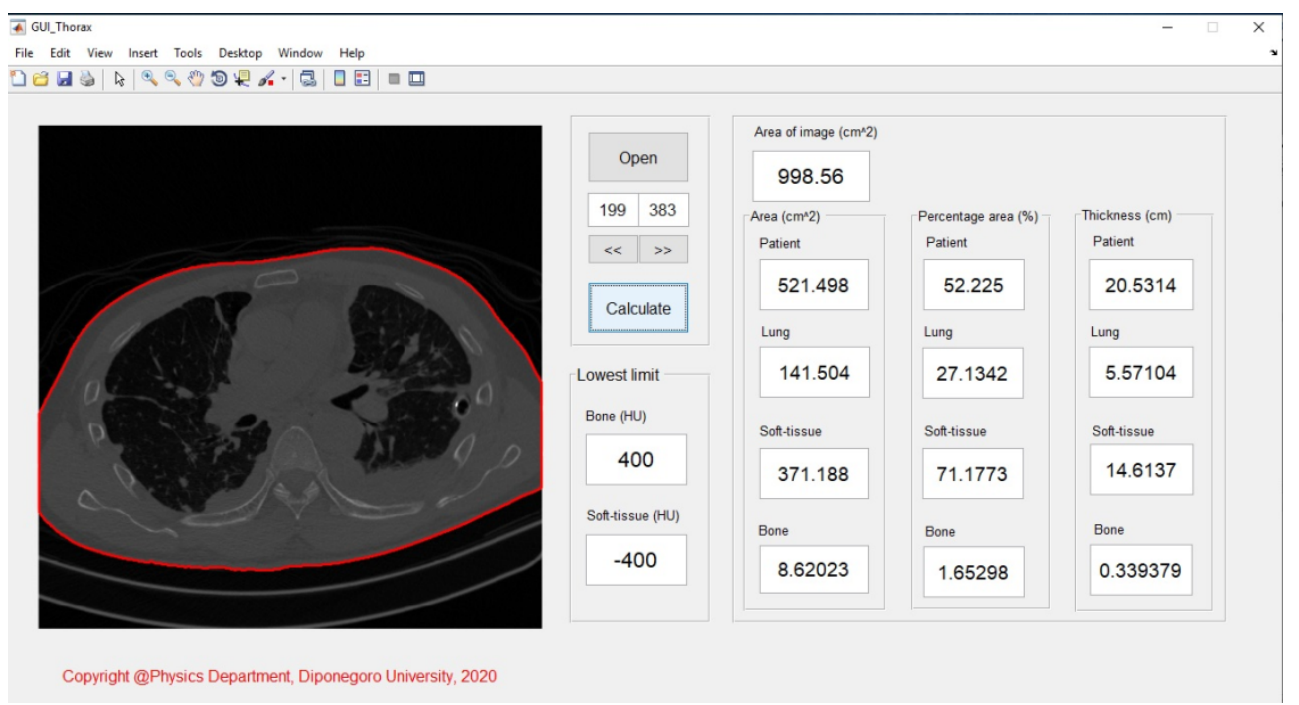

Figure 1. Screen capture of the GUI developed for calculating the areas of the main components of the chest of Indonesian patients.

To record the patient dose in DR examinations, a metric of entrance surface dose (ESD) is usually used. ${ }^{11}$ ESD can be directly measured at the surface of the patient's skin or using a dosimetrical phantom. The dosimetrical phantom is specifically developed from material with similar characteristics to human tissue and is used to simulate radiation interactions in the human body. ${ }^{12}$ The dosimetrical phantom generally used is the phantom equivalent to the patient (PEP). ${ }^{13}$ The PEP is made from Acrylic and Aluminum as it is developed by the American National Standard Institute (ANSI) or made from Lucide and Aluminum (LucAl) as it is developed by the Center for Devices and Radiological Health (CDRH). ${ }^{13}$ Both phantoms provide accurate simulations of primary and scattering transmission through the patient bodies. ${ }^{13-17}$ The PEP phantom is lightweight and easy to transport, and accurately simulates the patient's standard attenuation property. ${ }^{18,19}$

Several previous studies produced dosimetrical phantoms for DR examinations. ${ }^{21-28}$ A dosimetrical phantom is also available in the market, however, it is expensive and has been developed based on the body characteristics of European or American patients. ${ }^{20}$ Such phantoms generally have a larger size than the average Indonesian $^{29}$ so that the absorbed dose and amount of back-scattered radiation differ from Indonesian patients. In this study, we developed a software for determining the areas of the main components of the chest (soft tissue, bone, and air) based on chest computed tomography (CT) examination, and then implemented the results to compute the areas of the main chest components as preliminary data for developing a specific chest DR phantom for Indonesian patients.

\section{Methods}

We retrospectively studied all DR images, including basic chest examinations, from 2015 to 2019 from the Radiology Department of the Kraton Regional General Hospital, Pekalongan, Indonesia. We calculated the number of basic chest examinations and their percentage compared to all examinations.

We then developed a software using Matlab (Figure 1) for automatically computing the areas of the main components (soft tissue, bone, and air) from the chest CT examinations, in order to develop a specific chest phantom for DR in the hospital.

For selected images, we segmented the borders of each image using an algorithm introduced previously. ${ }^{30} \mathrm{We}$ then determined the chest component compositions based on the CT numbers in the Hounsfield Unit (HU) scale. We varied the three limits of $\mathrm{HU}$ for the main tissue compositions as follows: 1. The lower limit of soft tissue was $-200 \mathrm{HU}$ and the lower limit of bone was $+200 \mathrm{HU}, 2$. The lower limit of soft tissue was $-250 \mathrm{HU}$ and the lower limit of bone was $+250 \mathrm{HU}$, and 3 . The lower limit of soft tissue was $-300 \mathrm{HU}$ and the lower limit of bone was $+300 \mathrm{HU}$. Figure 2 shows a typical result of our image segmentation.

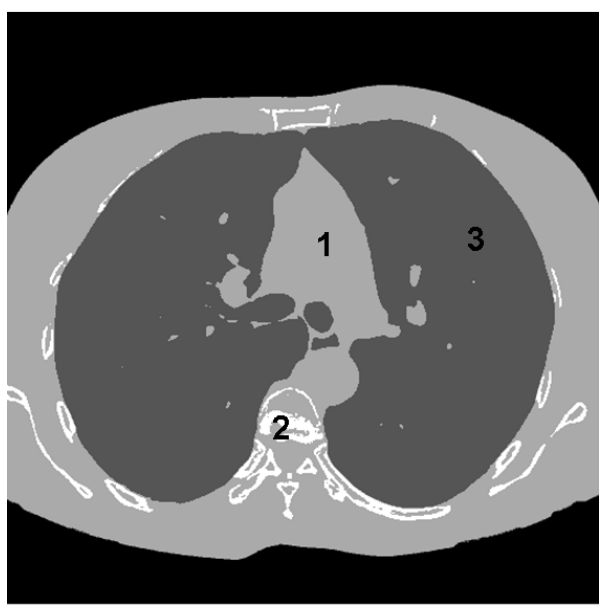

Figure 2. The resulting image segmentation to determine the areas of the main chest components. The lower limit of soft tissue was $250 \mathrm{HU}$ and the lower limit of bone was $+250 \mathrm{HU} .1$ indicates soft tissue, 2 indicates bone, and 3 indicates air. 
The areas of the main components of the chest were averaged from four slices from every patient. Figure 3 shows the scout image of the chest and slice positions for calculation of the main chest components, and Figure 4 shows the corresponding axial CT images for these four slices.

To investigate the main composition, we used chest CT patients with clinical indications of chest tumors scanned in 2019. The total number of patients was 102, with 62 male and 40 female patients. In terms of age 5-11 years (1 patient), 1225 years (4 patients), 26-45 years (20 patients), and $>45$ years (77 patients).

The main components of the chest data were tabulated to calculate the average value and standard deviations (SD) of the areas of soft tissue, bone, and air. The statistical differences

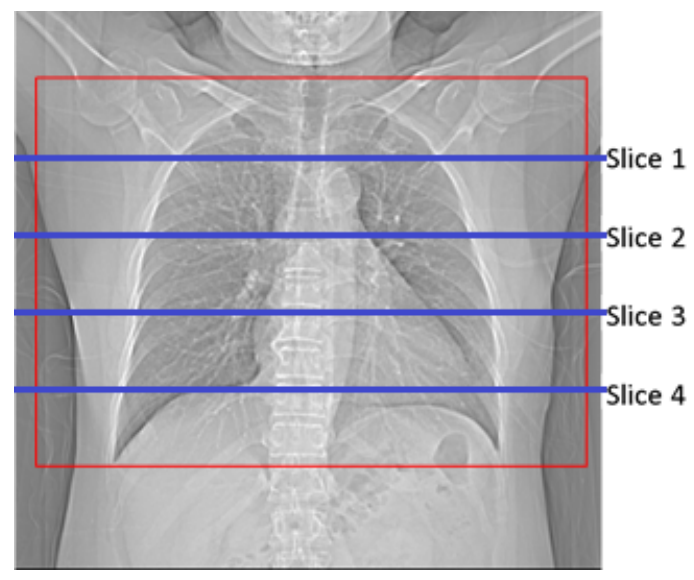

Figure 3. Example of a scout image of the chest. It shows four slices distributed along the chest for calculation of the areas of the main chest components.

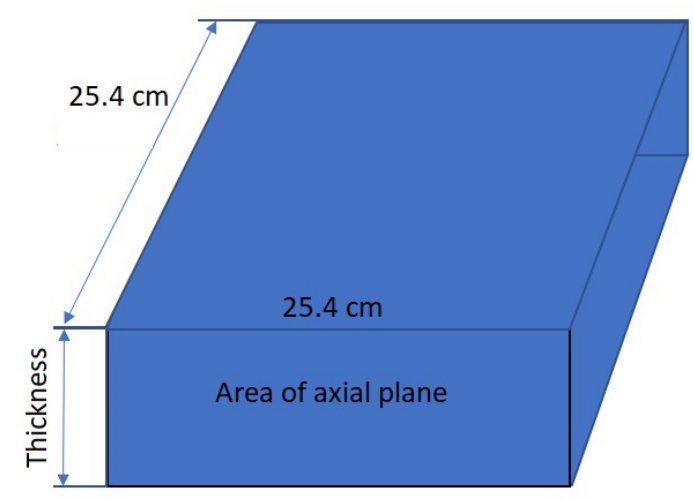

Figure 5. One slab of dosimetrical phantom between male and female patients, and among patient ages, were also computed.

The thickness of the phantom was calculated as the total area of the main chest components divided by $25.4 \mathrm{~cm}$. This is due to the area of the dosimetrical phantom slab was $25.4 \mathrm{~cm} \mathrm{x}$ $25.4 \mathrm{~cm}$ (Figure 5). ${ }^{13}$

\section{Results}

\section{Number of basic chest examinations}

Figure 6 shows that basic chest examination comprises more than half $(59.5 \%)$ of all radiological examinations in the Radiology Department of Kraton Regional General Hospital, during 2014-2019.
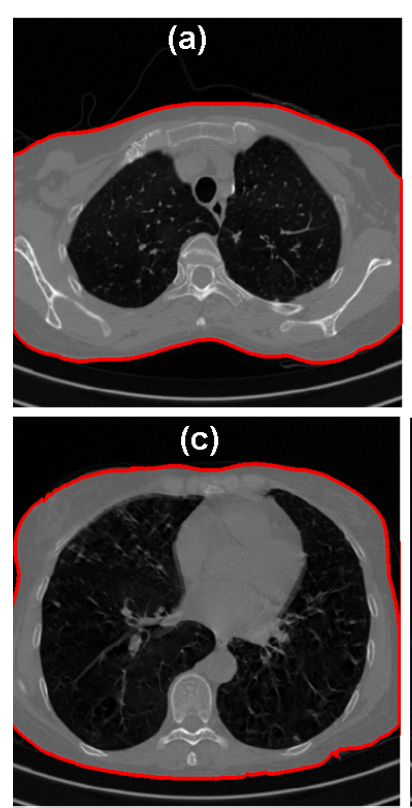

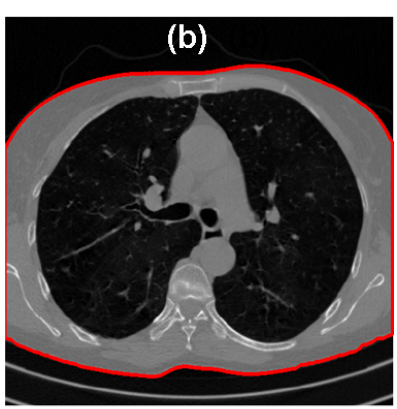

(d)

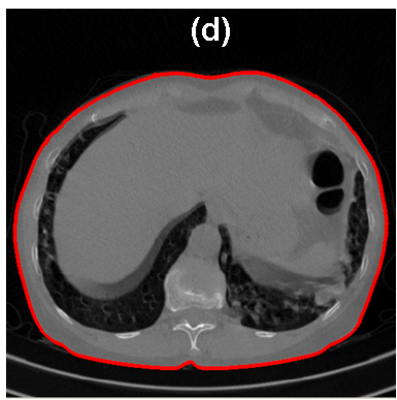

Figure 4. Four selected axial images for calculation of the areas of the main chest components. (a) Slice 1 - upper chest, (b) Slice 2 middle-upper chest, (c) Slice 3 - middle-lower chest, and (d) Slice 4 -lower chest.

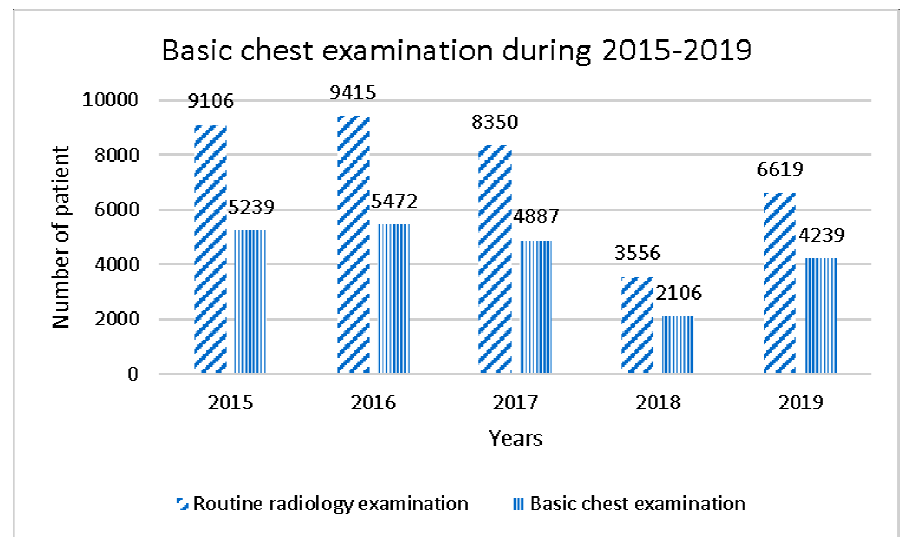

Figure 6. The numbers of basic chest examinations and all routine radiological examinations in the Kraton Regional General Hospital during 2015-2019. 


\section{Areas of the main components of the chest}

Figure 7 shows the original axial CT images of the chest and segmented images using different delimiters. The different delimiters had only a slight effect on the calculated areas of the main chest components. For further processing, we chose the lower limit of soft tissue as $-250 \mathrm{HU}$ and the lower limit of bone as $+250 \mathrm{HU}$.

\section{The main chest components based on gender}

The areas and thicknesses of the components (soft tissue, bone, and air) in the chest based on the gender of the patients are shown in Table 1. It indicates that the areas the three components in men are statistically larger than in women, with a p-value more than 0.05 .

\section{The main chest components based on patient age}

The areas and thicknesses of the main components of the chest based on patient age are tabulated in Table 2. It indicates that the widest areas of the soft tissue and bone are in 12-25 years, and the widest area of the air is in 26-45 years.

\section{Discussion}

The basic chest examination is often part of a medical checkup, and is carried out for various clinical pathways. It is the most performed examination in the Radiology Department of the Kraton Regional General Hospital comprising $59.5 \%$ of all routine examinations. This confirms previous studies which reported that the chest is the most common DR examination. ${ }^{31,32}$

For measuring entrance skin dose (ESD) of chest DR examination, a dosimetrical phantom is often used. Many dosimetrical phantoms have been developed, but a dosimetrical phantom specific for Indonesian chest DR examinations is not available.

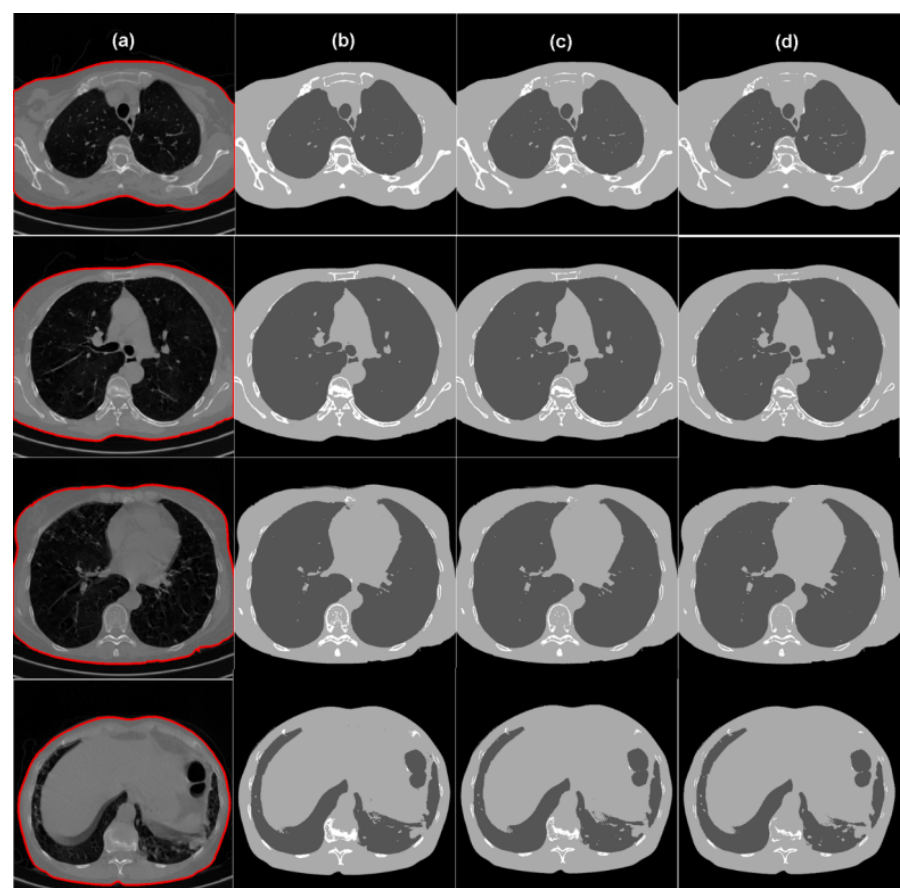

Figure 7. (a) Original images of patients, and segmented images using the lower limit of soft tissue and the lower limit of bone of (b) $-200 \mathrm{HU}+200 \mathrm{HU}$, (c) $-\mathbf{2 5 0} \mathrm{HU}$ and $+250 \mathrm{HU}$, and (d) $-300 \mathrm{HU}$ and $+300 \mathrm{HU}$ respectively.

We investigated axial CT images to determine the thickness of a putative dosimetrical phantom. Chest CT images obtained were processed to measure the areas of soft tissue, bone, and air in every slice using our GUI. Although various limits for the segmentation produced similar results, we preferred a limit of $-250 \mathrm{HU}$ for the lower limit of soft tissue and $+250 \mathrm{HU}$ for the limit lower of bone. If the lower limit for soft tissue is higher than -250 then fat tissue in the musculature might be detected as air, and if lower than -250 then air in the alveoli might be detected as soft tissue. And if the limit for bone is lower than +250 then minimal calcification in the blood vessels might be detected as bone, and if more than +250 then cartilage in the chest might not be detected as bone.

Table 1. The areas and thicknesses of main chest components based on gender.

\begin{tabular}{|c|c|c|c|c|c|c|c|}
\hline \multirow{2}{*}{ Number of patients } & \multirow{2}{*}{ Gender } & \multicolumn{3}{|c|}{ Area $\left(\mathrm{cm}^{2}\right)$} & \multicolumn{3}{|c|}{ Thickness (cm) } \\
\hline & & Soft tissue & Bone & Air & Soft tissue & Bone & Air \\
\hline 62 & Male & $345 \pm 84$ & $23 \pm 4$ & $139 \pm 52$ & $14 \pm 3$ & $0.9 \pm 0.2$ & $6 \pm 2$ \\
\hline 40 & Female & $309 \pm 85$ & $15 \pm 4$ & $103 \pm 42$ & $12 \pm 3$ & $0.6 \pm 0.1$ & $4 \pm 2$ \\
\hline
\end{tabular}

Table 2. The areas and thicknesses of the main chest components based on patient age.

\begin{tabular}{|c|c|c|c|c|c|c|c|}
\hline \multirow{2}{*}{ Number of patients } & \multirow{2}{*}{ Patient age (years) } & \multicolumn{3}{|c|}{ Area $\left(\mathrm{cm}^{2}\right)$} & \multicolumn{3}{|c|}{ Thickness (cm) } \\
\hline & & Soft tissue & Bone & Air & Soft tissue & Bone & Air \\
\hline 1 & $5-11$ & $121 \pm 0$ & $10 \pm 0$ & $55 \pm 0$ & $5 \pm 0$ & $0.4 \pm 0.0$ & $2 \pm 0$ \\
\hline 4 & $12-25$ & $371 \pm 77$ & $27 \pm 3$ & $88 \pm 59$ & $15 \pm 3$ & $1.1 \pm 0.1$ & $4 \pm 2$ \\
\hline 20 & $26-45$ & $322 \pm 78$ & $22 \pm 5$ & $131 \pm 46$ & $13 \pm 3$ & $0.9 \pm 0.2$ & $5 \pm 2$ \\
\hline 77 & $>45$ & $334 \pm 86$ & $19 \pm 5$ & $126 \pm 52$ & $13 \pm 3$ & $0.8 \pm 0.2$ & $5 \pm 2$ \\
\hline
\end{tabular}


The chest areas in males and females have a significant difference as seen Table 1. Statistical tests reveal that male patients have greater chest constituent areas than females ( $p$ > 0.05). Our measurements show a dependency of area on age (Table 2), so that a dosimetrical phantom should take into account both these differences. The thicknesses of soft tissue, bone, and air are $14 \pm 3,0.9 \pm 0.2$, and $6 \pm 2 \mathrm{~cm}$ for male patients, and $12 \pm 3,0.6 \pm 0.1$, and $4 \pm 2 \mathrm{~cm}$ for female patients. A previous study reported that the thicknesses of soft tissue, bone, and air are $13.3,2.3$, and $5 \mathrm{~cm}$ respectively. ${ }^{25}$ Therefore, the results of our study are comparable to the previous study. ${ }^{25}$ Pina et $\mathrm{al}^{25}$ provided that thickness of soft tissue could be converted to a thickness of Lucite by the conversion factor of 1.391, and thickness of bone could be thickness to Aluminum by a conversion factor of 0.174 .

We limited our investigation to the three main components of the chest, in line with previous studies. ${ }^{16,21,23,25}$ In dosimetrical phantoms, soft tissue is often replaced with lucite/acrylic, bone with aluminum, lung/air chest with air. ${ }^{16,21,23}$ In this study, the thickness of the phantom was calculated as the total area of the main chest composition divided by $25.4 \mathrm{~cm}$, due to the area of the dosimetrical phantom slab was $25.4 \mathrm{~cm} \mathrm{x} 25.4 \mathrm{~cm}$ This is valid for adult patients. However, for pediatric patients, the thickness should be divided by $15 \mathrm{~cm}$.

We limited our measurement of areas to only 4 slices, namely the upper chest, middle-upper chest, middle-lower chest, and lower chest. Our sample numbers were small, especially for ages of 5-11 years because the chest CT examination is very rarely used at this age in the hospital. All the images used were from patients who had chest complaints (shortness of breath, suspected chest tumors, etc.), so the area measurements may differ for patients who do not experience chest complaints.

\section{Conclusion}

We have successfully developed a MatLab GUI for measuring the areas of soft tissue, bone, and air in a chest CT image, specifically for Indonesian patients. The GUI can be used to automatically calculate the areas of the main components of the chest by determining the lower limit of the bone and the lower limit of the soft tissue. Implementation in our hospital showed that the chest compositions in male and female patients have different areas and thicknesses, and are dependent on the age of the patient. Based on our result, a physical dosimetrical phantom for chest DR examinations for Indonesians could be realized.

\section{Acknowledgments}

This work was funded by the Riset Publikasi Internasional Bereputasi Tinggi (RPIBT), Diponegoro University (Contract Numbers: 329-116/UN7.6.1/PP/2020).

\section{References}

1. Gonzalez AJ. Current status on the global levels of radiation exposure. Proceedings of the International Conference on the Sources, Effects and Risks of Ionizing Radiation. 2014;16-54.

2. Hiswara E, Kartikasari D. Dosis pasien pada pemeriksaan rutin sinar-x radiologi diagnostik. Indonesian Journal of Nuclear Science and Technology. 2015;16:71-84.

3. Salat D, Nikodemova D. Patient doses and image quality in digital chest radiology. Radiat Prot Dosimetry. 2008;129:147-149.

4. Paydar R, Takavar A, Kardan MR, Babakhani A, Deevband MR, Saber S. Patient effective dose evaluation for chest X-ray examination in three digital radiography centers. Iran J Radiat Res. 2012;10:139-143.

5. International Commission on Radiation Units and Measurements. Image quality in chest radiography. ICRU Report 70. 2003.

6. Moey SF, Fatin Naimah MA. Evaluation of the influence of exposure index on image quality and radiation dose. Iran J Med Phys 2019;16:294-299

7. Adhikari SR. Effect and application of ionization radiation (X-ray) in living organism. Kaski. The Himalaya Physics. 2012;3:89-92.

8. Rana BS, Kumar S, Sandhu IS, Singh NP. Dosimetry of adult and pediatric patients for common digital radiography examinations. Radiat Prot Dosimetry. 2018;179:349-357.

9. Sandborg M, Tingberg A, Ullman G, Dance DR, Alm Carlsson G. Comparison of clinical and physical measures of image quality in chest and pelvis computed radiography at different tube voltages. Med Phys. 2006;33:4169-4175.

10. Komite Akreditasi Rumah Sakit. Standar nasional akreditasi rumah sakit edisi 1. 2017.

11. Martin CJ. Radiation dosimetry for diagnostic medical exposures. Radiat Prot Dosimetry. 2008;128:389-412.

12. International Commission on Radiation Units and Measurements. Phantoms and computational models in therapy, diagnosis and protection. ICRU Publication 48 (Oxford: Pergamon Press). 1992.

13. American Association of Physicists in Medicine. Standardized methods for measuring diagnostic X-ray exposures. AAPM Report No 31. 1990.

14. American National Standard Institute. Method for the sensitometry of medical X-ray screen-film-processing systems. American National Standard Institute (PH2/43). New York. 1982. 
15. Conway BJ, Butler PF, Duff JE, et al. Beam quality independent attenuation phantom for estimating patient exposure from X-ray automatic exposure controlled chest examinations. Med Phys. 1984;11:827-832.

16. Pina DR, Duarte SB, Ghilardi Netto T, Morceli J. Phantom development for radiographic image optimization of chest, skull and pelvis examination for nonstandard patient. Appl Radiat Isot. 2009;67(1):61-69.

17. Gray JE. Quality control in diagnostic imaging: A quality control cookbook. Baltimor Md: University Park Press.1983.

18. Conway BJ, Duff JE, Fewell TR, Jennings RJ, Rothenberg LN, Fleischman RC. A patient-equivalent attenuation phantom for estimating patient exposures from automatic exposure controlled X-ray examinations of the abdomen and lumbosacral spine. Med Phys. 1990;17(3):448-453.

19. Conway BJ, Suleiman OH, Rueter FG, Mccrohan JL. Patient equivalent attenuation phantoms. Radiat Prot Dosimetry.1992;43(14):123-125.

20. International Commission on Radiological Protection. Basic anatomical and physiological data for use in radiological protection: Reference values. ICRP Publication 89 (Oxford: Pergamon press). 2003.

21. Alves AFF, Miranda JRA, Bacchim Neto FA, Duarte SB, Pina DR. Construction of pediatric homogeneous phantoms for optimization of chest and skull radiographs. Eur J Radiol. 2015;84(8):1579-1585.

22. Chotas HG, Floyd CE Jr, Johnson GA, Ravin CE. Quality control phantom for digital chest radiography. Radiology. 1997;202(1):111-116.

23. Jones AK, Simon TA, Bolch WE, Holman MM, Hintenlang DE. Tomographic physical phantom of the newborn child with real-time dosimetry I. Methods and techniques for construction. Med Phys. 2006;33:3274-3282.

24. Kim JI, Choi H, Lee BI, et al. Physical phantom of typical Korean male for radiation protection purpose. Radiat Prot Dosimetry. 2006;118:131-136.

25. Pina DR, Duarte SB, Morceli J, Ghilardi Netto T. Development of phantom for radiographic image optimization of standard patient in the lateral view of chest and skull examination. Appl Radiat Isot. 2006;64:1623-1630.

26. Rasuli B, Mahmoud-Pashazadeh A, Ghorbani M, Juybari RT, Naserpour M. Patient dose measurement in common medical X-ray examinations in Iran. J Appl Clin Med Phys. 2016;17(1): 374-386.

27. Winslow JF, Hyer DE, Fisher RF, Tien CJ, Hintenlang DE. Construction of anthropomorphic phantoms for use in dosimetry studies. J Appl Clin Med Phys. 2009;10(3):195-204.

28. Jones AK, Hintenlang D, Bolch WE. Tissue equivalent materials for construction of tomographic dosimetry phantoms in pediatric radiology. Med Phys. 2003;30:2072-2081.

29. Fahmi A, Anam C, Suryono, Ali MH, Jauhari A. Correlation between age and head diameters in the paediatric patients during CT examination of the head. Pol J Med Phys Eng. 2019;25(4):229-235

30. Anam C, Haryanto F, Widita R, Arif I, Dougherty G. Automated calculation of water equivalent diameter (DW) based on AAPM task group 220. J Appl Clin Med Phys. 2016;17(4):320-333.

31. Lin CS, Chan PC, Huang KH, Lu CF, Chen YF, Chen YOL. Guidelines for reducing image retakes of general digital radiography. Advances in Mechanical Engineering. 2016;8(4):1-6.

32. Qin C, Yao D, Shi Y, Song Z. Computer-aided detection in chest radiography based on artificial intelligence: a survey. BioMed Eng OnLine. 2018;17:113. 